Abbott Laboratories

Biaxin, 291-294

\section{American Osteopathic}

Association

36th Annual Research

Conference, 375

Centennial Care-A-Van Project, 308

Items Available, 300

Basel Pharmaceuticals

Habitrol, 275-283

\section{SURGICAL RESIDENTS/FELLOWS}

Clinical residency/fellowship positions available in adult and pediatric cardiothoracic surgery.

- Large volume of cases - New Jersey license required -Excellent salary and benefits

Please contact:

Lynn B. McGrath, MD Chairman, Dept. of Surgery

(609) 893-6611, Ext. 359

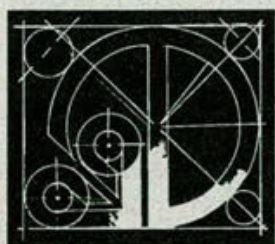

Deborah Heart and Lung Center 200 Trenton Road Browns Mills, NJ 08015
Ciba Pharmaceutical

Company

Lotensin, 263-267

Curatek Pharmaceuticals

MetroGel, 373, 374

Deborah Heart and Lung

Center, 390

Flint Osteopathic Hospital, 289

Geigy Pharmaceuticals

Lopressor, 307, 345, 346

Voltaren, 363,364

GenDerm Corporation

Zostrix, 256, 257

Glaxo Pharmaceuticals

Zinacef, 367, 368

JSA, Inc., 311

Eli Lilly and Company

Ceclor, 242-244

Marion Merrell Dow Inc.

Cardizem, 325, 326

Cardizem CD, 355, 356

Seldane, 303-306, Cover 3

McNeil Consumer Products

Co.

Pediaprofen, 285, 286, 314

Tylenol, 301
G. D. Searle and Co.

Calan SR, 335, 336

Cytotec, 315,316

National Osteopathic

Foundation

Mead Johnson Awards, 302

Parke-Davis

Dilantin Kapseals, 309, 310

Lopid, 358-360

Pfizer Labs Division

Feldene, 270-272

Procardia XL, 297, 298

Roche Laboratories

Medical Director's Page, 259

Roche Products Inc.

Valium, 269

Roerig Division, Pfizer

Incorporated

Cardura, Cover 2-1, 313

SmithKline Beecham

Augmentin, 260, 261

Relafen, 247-255

Tagamet, Cover 4

The Upjohn Company

Xanax, 287, 288

Whitehall Laboratories Inc. Advil, 240 
Seldane $e^{\circledast}$

(terfenadine) $60 \mathrm{mg}$ Tablets

BRIEF SUMMARY

CAUTION Federal law prohibits dispensing without prescription.

DESCRIPTION

Seldane (tertenadine) is arailable as tablets for oral administration. Each tablet contains $60 \mathrm{mg}$ terfenastine. Tabbets also contain, as inactive ingredients: com starch, getatin, batose, magnesium stearate, and sodum bicarbonate.

INOICATIONS AND USACE

Selldane is indicated for the relief of symptoms associated with seasonal allergic thinitis such as sneezing, tininornea. pruntus, and lacrimation.

CONTRAMOICATIONS

Seldane is contraindicated in patients with a known hypersensitivity to terlenadine or any of tis ingredients.

General: Terfenadine undergoes extensive metabolism in the liver. Patients with impaired hepatic

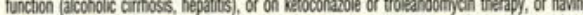

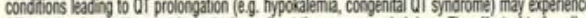
OT prolongation and or venticicular tactycardia at the recommended dose. The effect of tertenadine in patients who are receving agents which ater the of interval is not knom. These events have also cocurred in patients on maccoide antbiotics, including enythromycin, but causality is unclear. The everts may be relatied to attered metabolism of the dryg. 10 electroyte imbalance, or bothIntormation for aatients: Patients taking Sellane should receive the following intormation and in structions. Anthistamines are prescribed to reduce allergic symptoms. Patients should be Questioned about pregnancy or lactation before starfing Sellane therapy, since the drug should be

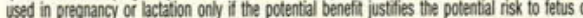
baby. Pationts should be instructed to the Seldane only as needed and not to exoced the prescribes dose. Patenth sthould also be instructed to store this medication in a tight'y closed container in a

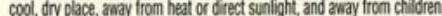

Orug Interactions: Preliminary evidence exists that concurrent ketoconazole or macrolide administration significanty a alters the metaboism of tertenadine. Concurrent use of Seldane with ketoconazole or frokandomycin is not recommended. Concurrent use of other macrolides should be approached with caution.

Carchoogenesis, mutagenesis, impaimment of fertitity. Oral doses of tertenadine, corresponding to 63 times the recommended human daily dose, in mice for 18 months or in rats for 24 months revealed no evidence of tumorigencity. Microbial and micronucleus test assays with tertenadine have reveled no evidence of mutagenesis

Reproduction and fertility studies in rats showed no effects on mele or female fertility at oral doses of un to 21 times the human daily dose. At 63 fimes the human daily dose there was a small but significant reduction in implants and at 125 fimes the human daily dose rediced implants and increased post-mplantation losses were observed, which were iudged to be secondary to maternal toncily.

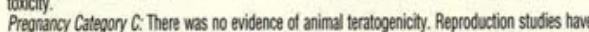

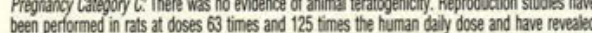

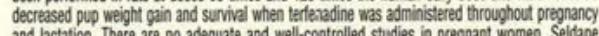
and lactation. There are no adequate and well-controlled studies in pregnant women. Seldan

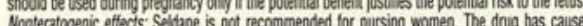
decreased pup weight gain and survival in ats given doses 63 times and 125 times the human dail dose throughout pregnancy and lactrion Efftects on pups emosesed to Seltane onty diving lactation

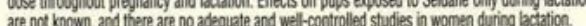
Pediatic use' Sately and effectiveness of Seldane in children below the age of 12 years have not been estabished.

AOVERSE REACTIONS

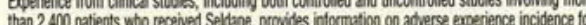

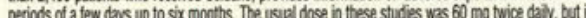
asmater

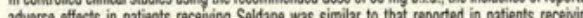
placebo. (See Tatle below.)

ADVERSE EVENTS REPORTED IN CUMICAL TRIALS

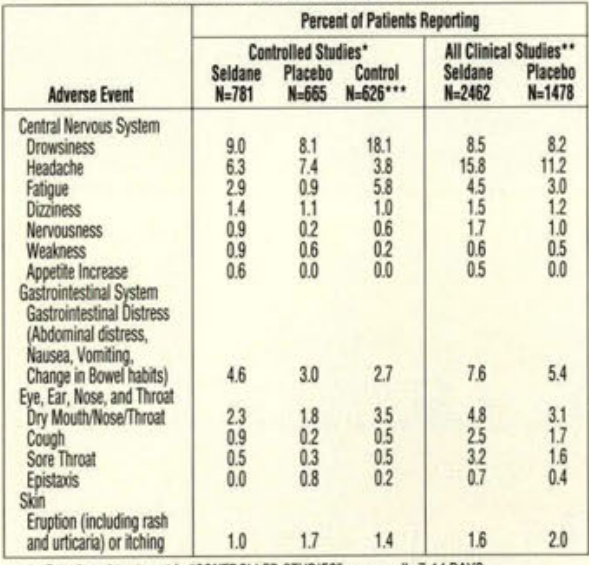

- Duration of treatment in "CONTROLLED STUDIES" was usually 7-14 DAYS.

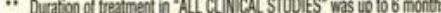

. CONTROL DRUGS: Chlorpheniramine (291 patients), d-Chlorpheniramine (189 patients), Clemastine (146 pateents)

Rare reports of severe cardiovascular adverse effects have been received which include arntythmias (venticular tachyarthythmia, torssdes de pointes, ventricular fibrilation), hypotension, palpatations

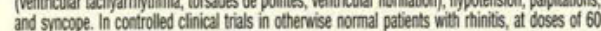
ang bid small increases in QTc interval were obsened. Changes of this magnitude in a normal

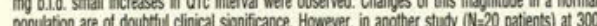
mo bid. a mean increse in QTc of $10 \%$ (range $-4 \%$ to $+30 \%$ ) (mean increase of $46 \mathrm{msec}$ ) wes mg bic. a mean hatese in

observed without cinical signs or symptoms.

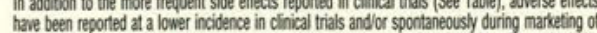

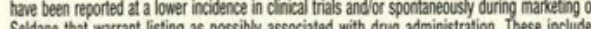

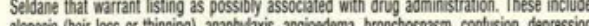

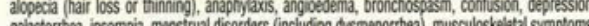

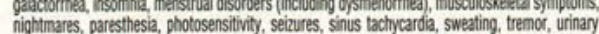
nightmares, paresthesia, photosents

Irequency, and visul dosctuance.

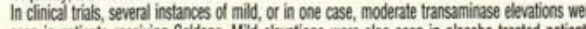
seen in patents recereving Seldane. Mili elavations were also seen in placebo treated patients. Marketing experiences indoder solated repons at mostc cases arvaliable information is incomplete:

\section{OVERDOSAG:}

Intormation concerning possible overdosige and its treatment appears in ful Prescribing Intormation. DOSAGE ANO ADMINISTRATION

One tablet $(60 \mathrm{mg})$ ) wice daily for adults and children 12 years and older. Product hrormaton as of July, 1990

MARION MERRELL DOW INC.

Prescription Products Division

Kanses City, MO 64114

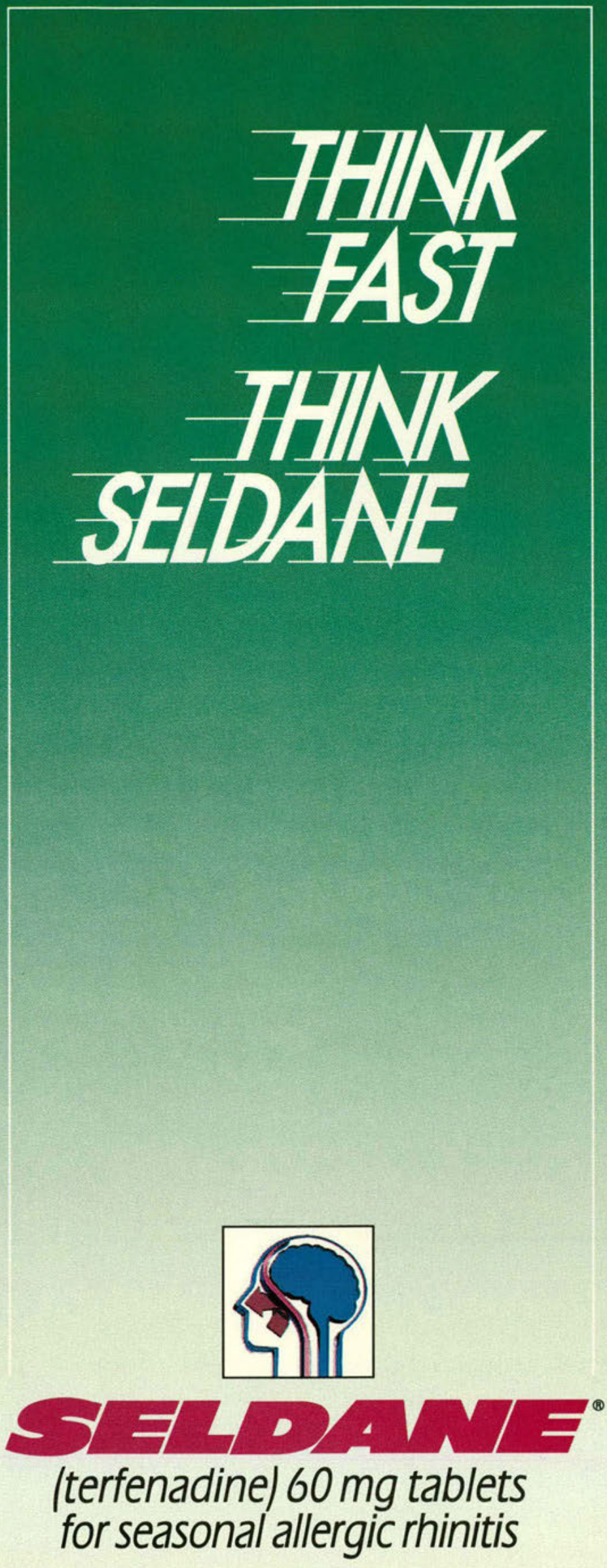

Please see the brief summary of prescribing information.

() 1991, Marion Merrell Dow Inc

SELAF656/A4043 
Indications and Usage: II Short-term treatment of active duodenal uicer, (2) maintenance therapy for duodenai uicer pabients at reduced dosage after heal. ing of active ulcer, (3) shoriterm treatment of active benign gastric ulcer; (4) erosive gastroesophageal reflux cisease; (5) prevention of upper gastrointestinal bleeding incribically all patients, (6) treatment of pathological hypersecretory conditions. Contraindications: Tagamet is contraindicated for patients known to have hypersensitivity to the product

Precautions: Rare instances of cardiac arrhythmias and hypotension have been reported following the rapid administration of Tagamet/cimetidine hydrochloride)

Symptomacic response to tagamet therapy does not prectude the presence ol a gastix

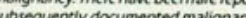

Reversible confusional states have been observed on occasion, predominantly in severely ill patients.

tagamet has been reported to reduce the hepatic metabolism of warfarinoype anticoagulants phenytoin, propranolid, nifedipine, chiordiazepoxide, diazepam, certain tricycic antidepressants, hidocaine, theophyline and metronidazole. Clinically signift. cant effects have been reported with the warfarin anticoagulants: therefore, dose montoring or proctromoin time is recommended, and adjustment of the antcoagulant cose may be necessary when tagamet is administered concomitantly. produce adverse clinical effects

However, a crossover study in healthy subjects receiving either Tagame:

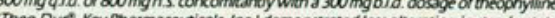

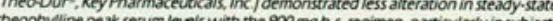
a s a receiving theophylline should be monitored appropriately regardless of patients tant drug therapy!

In a 24-month toxicity study in rats, at dose levels approximately 8 to 48 times the

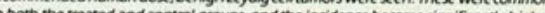
only in the ased rats receiving Togamet.

A weak antiandrogenic effect has been demonstrated in animals. in human studie: Agamet has been shown to have no effect on spermatogenesis. sperm count motility

Pregnancy Category B: Reproduction studies have been performed in rats, raboits and mice at doses up to 40 times the norma/ human dose and have revealed no evidence of impaired fertility or harm to the fetus due to tagamet. There are, howevet, no ade quate and well-controlied studies in pregnant women. Because animal reproductive studies are not always predictive of human response, this drug should be used during

Lack of experience to date predudes recommending tagamet for use in children under 16 uniessantiparedoenefis outweigh pocential risha, generanty, nursing should not be undertaken by patients taking the drug since cimetidine is secreted in human milk. Adverse Reactions: Diarthea, dizziness, somnolence, headache. Reversible con fusiona states $/$ eg., mental confusion, agitation, psychosis, depression, anxiety. hallucinations, disorientation), predominantly in severely ill patients, have been reported. Reversible impotence in patients with pachological hypersectetory disorders receiving tagamet particularly in high doses for at leas 12 monerss has been reported. The incidence of imporence in large-scale surveillance studies at regular doses has nor exceeded thatcomence cell counts in Taganes treated for one month or longer. Decreased whice bibod including agranulogrosis (approximuely 3 per milion patients/ have, 000 patients). including a few reports of recurrence on rechallenge Mons these seports were in

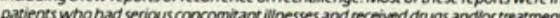
known to produce neutropenia. Thrombocytopenia /approximately 3 per million patients/ and, very ravely, cases of pancrtopenia or aplastic anemia have also been

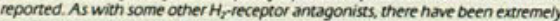
fare reports of immune hemolytic anemia. Dose-related increases in serum transaminase have been reported. Reversible adverse hepatic effects, cholestaticor mixed cholestatichepatoceilular in nature, have been reported rarely. Because of the predominance of cholestatic features, severe parenctym mar ingury is considered highly unikely. A single case of biopsy-proven periponta/ hepatic horosis in a patient recerving have been reported pare cases of fores intersatial nephritis, pancrearitis and allergic reactions, including anaphytaxis and hypersensitivity vasculitis, have been reported Rare cases 0 toradycardia

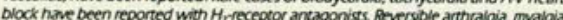
and exacerbation of joint symptoms in patients with preexisting anthritis have been reported rarely Rare cases of polymyositis have been reported, but nocausal retation ship has been established. Mild rash and, very ravely, cases of severe generalized skin reactions /eg. Stevens.Johnson syndrome, epidermal necrolysis, erythema multiforme, exfoliative oermatitis and generalized exfoliative eryatroderma/ have been reported with Hy-receptor antagonists. Reversible alopecia has been reported very

How Supplled: Tablets 200 mg tablets in bottles of 100; 300 mg tablets in bottles of 100 and Single Unit Packages of 100 /intended for institutional use onilyt: $400 \mathrm{mg}$ tablets in botzies or bo and single Unit Packages of 1 w/intended lor institutional use onlyy. and $800 \mathrm{mg}$ Titab tablets in bottles of 30 and Single Unit Packages of 100 Iintended for institutional use onily.

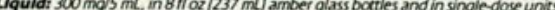
$1300 \mathrm{mg} / 5 \mathrm{~mL}$ ), in packages of 10 /intended for institutional use only.

Injection:

Vials: $300 \mathrm{mg} / 2 \mathrm{~mL}$ in single-dose vials, in packages of 25 , and in $8 \mathrm{ml}$ muthidose vials, in packages of 10 and 25 .

Single-Dose Premixed Plastic Contalners $300 \mathrm{mg}$ in $50 \mathrm{~mL}$ or $0.9 \%$ Sadium Chloride in single dose plastic containers, in packages of 4 units. No preservative has Chloride in sing

Exposure of the premixed product to excessive heat should be avoided. It is recommended the product be stored at controlled room temperature. Brief exposure up to

ADD-Vantage "Vlats $300 \mathrm{mg} / 2 \mathrm{~mL}$ in single dose $A D D$ Vantage" Vials in packages

Tagamet/cimedidine hydroctioride/ injection premixed in single dose plastic containers is manufactured for Smich Kinne Beecham Pharmaceuticals by Baxter Healthcare Corporation, Deerfield, 11. 60015.

Bes-TG:18)
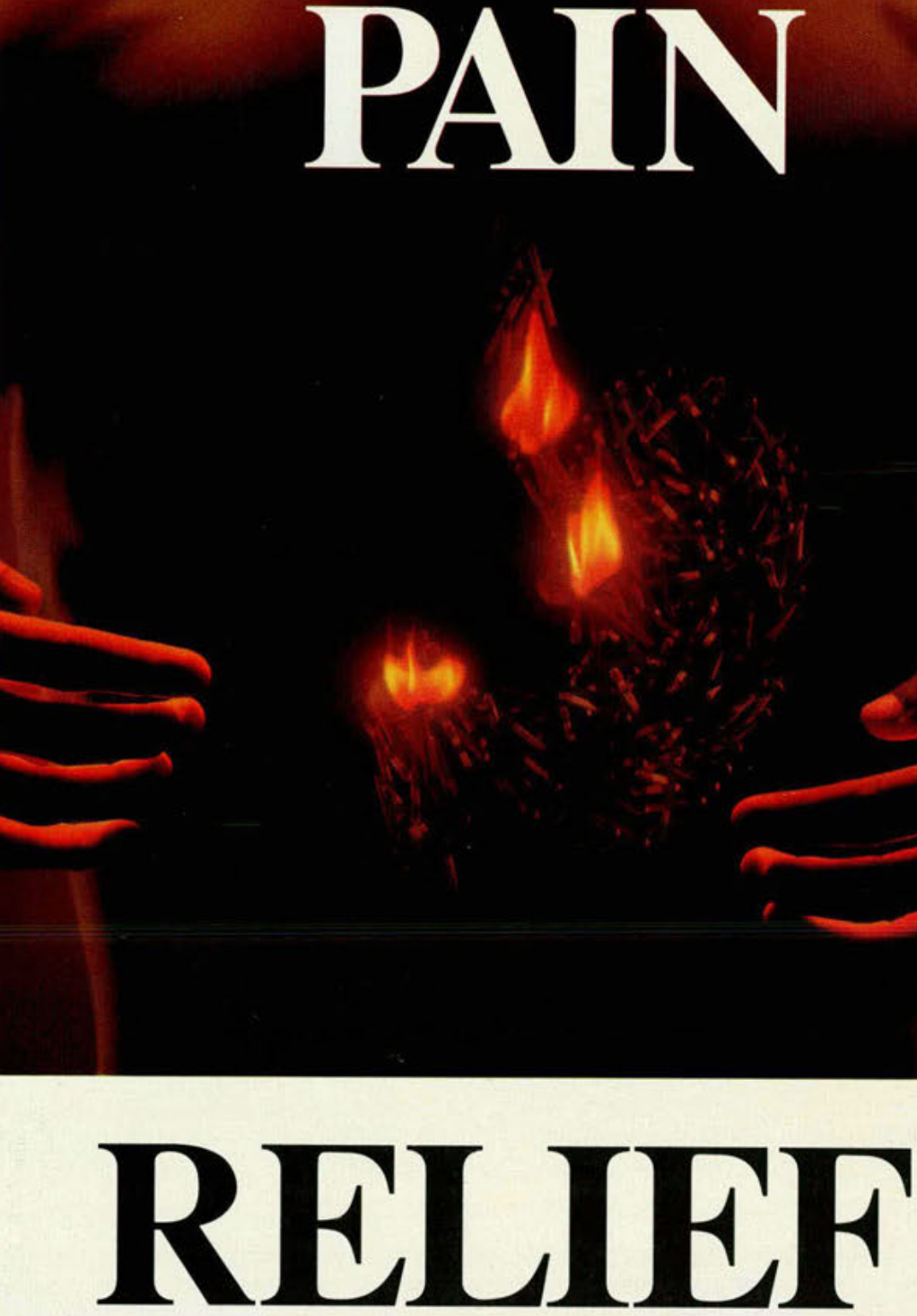

\section{Put out the fire fast with Tagamet}

In acute duodenal ulcer:

400 mg b.i.d./800 mg Tiltab ${ }^{\otimes}$ Tablets h.s.

In erosive esophagitis: $800 \mathrm{mg}$ b.i.d.
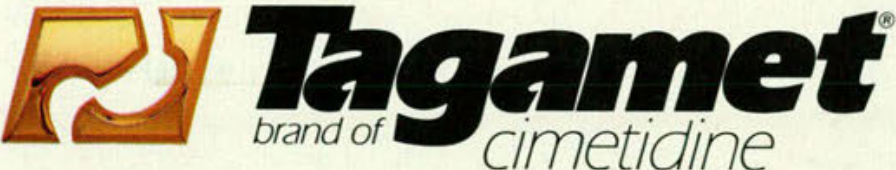